\title{
Evaluation of Applicability of Unconventional Cooling Method in Injection Mould
}

\section{Thang Nguyen Vo, Martin Seidl}

Faculty of Mechanical Engineering, Department of Engineering Technology, Technical University of Liberec. Studentská 2, 46117 Liberec. Czech Republic. E-mail: petrnguyen321@gmail.com, martin.seidl1@ @ul.cz

To increase the intensity of cooling the unconventional methods can be used, which enable to achieve quick and steady heat transfer from the injection mould and from the plastic product. This paper is devoted to the cooling method based on high cooling potential of liquid carbon dioxide that is included among the unconventional methods of mould temperature control system. The main objective of this paper is to evaluate the applicability of cooling with using liquid $\mathrm{CO}_{2}$ in the injection mould with regard to several aspects that have a direct impact on the final cooling efficiency. The practical experiment deals with the design of the shaped mould insert with the incorporated progressive cooling system by means of $\mathrm{CO}_{2}$ and its comparison with conventional tempering by water. The study is based on evaluations of the temperature profiles reached from thermocouples located in three positions in the injection mould and analysis of temperature fields measured on the surface of the product after its removal from the shaped insert. All the analyses were carried out for three cooling modes and before individual testing steps the technological parameters of cooling were optimized.

Keywords: Injection Mould, Unconventional Cooling, Liquid Carbon Dioxide, $\mathrm{CO}_{2}$

\section{Acknowledgement}

This paper was written at the Technical University of Liberec with the support of the Specific University Research Grant SGS, as provided by the Ministry of Education, Youth and Sports of the Czech Republic in the year 2016.

\section{References}

[1] Information on http://scifun.chem.wisc.edu/chemweek/pdf/carbondioxide.pdf

[2] Information on http://www.ascoco2.com

[3] Information on http://www.mathesongas.com/industrialgas/pdfs/bulk-carbon-dioxide.pdf

[4] NOVÁKOVÁ, I., SEIDL, M., BRDLÍK, P., ŠTVERÁK, J., MORAVEC, J. (2015). In: Cooling thin parts of pressure casting moulds by means of liquid $\mathrm{CO}_{2}$, Vol. 669, pp. 71-78. TU of Liberec. 